\title{
The Potential Role of the Endogenous Opioid System in the Antidepressant Effect of Ketamine
}

\author{
Botros B. Kostandy Shenoda \\ Pharmacology and Physiology Department, College of Medicine, Drexel University, Philadelphia, \\ USA
}

Correspondence should be addressed to: Botros B. Kostandy Shenoda; bbs39@drexel.edu

Received 20 September 2013; Accepted 3 December 2013; Published 31 January 2014

Academic Editor: Ewa J. Poleszak

Copyright (C) 2014 Botros B. Kostandy Shenoda. Distributed under Creative Commons CC-BY 3.0

\begin{abstract}
The noncompetitive NMDA receptor blocker ketamine provides significant improvement to patients suffering from depression but its mechanistic pathways are not fully understood. The endogenous opioid system is known to be dysregulated in patients with depression. Ketamine is known to interact with the opioid system either directly or indirectly through the release of endogenous opioids. In this review, I am discussing the potential role that might be played by the endogenous opioid system in conferring the antidepressant effect of ketamine and emphasizing that the modulation of the opioid system by ketamine warrants in-depth investigation for potential antidepressant effect.
\end{abstract}

Keywords: Ketamine, Endogenous opioids, Depression.

\section{Introduction}

Major Depressive Disorder (MDD) is a major public health problem. Current treatment options fail to achieve adequate remission in about $30 \%$ of the patient population (Rush et al., 2006). Recent studies have shown that drugs that modulate the glutamatergic transmission seem to be a promising tool in the management of Treatment Resistant Depression (TRD) (Connolly and Thase, 2012).

Ketamine is N-methyl-D-aspartate receptor (NMDAR) antagonist that has been used for more than half a century as intravenous anesthetic. Several studies have reported the antidepressant effect of ketamine and now it is well recognized as alternative option in the management of TRD (Mathew et al., 2012). Ketamine is unique in providing acute response in depressed patients (Dowben et al., 2013). This issue warrants an in depth investigation of the underlying molecular mechanisms which are, up to date, still unclear. Understanding the mode of action of ketamine will have a great impact on the efforts for the development of drugs with rapid onset and devoid of untoward effects commonly associated with ketamine, thus paving the way for the generation of the much needed second generation antidepressants (Machado-Vieira et al., 2009a). Ketamine has been known for modulating the endogenous opioid system and in this review, I am discussing an opioid-mediated

Cite this Article as: Botros B. Kostandy Shenoda (2014), "The Potential Role of the Endogenous Opioid System in the Antidepressant Effect of Ketamine," Research in Neurology: An International Journal, Vol. 2014 (2014), Article ID 733320, DOI: 10.5171/2014.733320 
action by which ketamine may produce its antidepressant effect. This review is an invitation for researchers to consider the investigation of the opioid-ketamine link shedding more light on the pharmacology of ketamine and the pathophysiology of depression.

\section{The Efficacy of Ketamine in Depression}

The first evidence for the antidepressant effect of ketamine was published in 2000, when ketamine infusion at subanesthetic dose $(0.5 \mathrm{mg} / \mathrm{kg})$ provided relief to patients with MDD (Berman et al., 2000). In 2006, the same dose was found to be effective in TRD (Zarate et al., 2006) and this was followed by many clinical trials showing the remarkable antidepressant effect of ketamine (aan het Rot et al., 2010; DiazGranados et al., 2010; Larkin and Beautrais, 2011; Machado-Vieira et al., 2009b; Mathew et al., 2010). In addition, a plethora of studies showed that ketamine clearly possess an antidepressant-like activity in animal models of depression (Garcia et al., 2008a,b; Koike et al., 2011). Its rapid onset of action and its effectiveness in TRD make ketamine one of a kind drug among available medications in these states. Despite these promising results, treatment with ketamine comes with certain considerations (Yang et al., 2012). Though a single intravenous infusion resulted in significant improvement in bipolar depressive patients, there were patients who remained resistant to ketamine (Rybakowski et al., 2013) and the effect was occasionally short lived, lasting for few days in some reports (Thakurta et al., 2012) which could be attributed to the pharmacokinetic properties of ketamine (Zarate et al., 2012). Tolerance has been reported to occur as rapid as the second dose in some cases (Liebrenz et al., 2009). Sedation, psychomimetic symptoms and euphoria are important limitations to ketamine therapy (Dillon et al., 2003), although some reports indicate the mild nature of these side effects (Dowben et al., 2013). The use of relatively low dose ketamine which is effective in alleviating symptoms of depression provides an advantage by producing less side effects associated with higher doses (Bunney and Bunney, 2012), but still these issues should be highly considered in treating patients with co-morbid psychiatric disorders.

\section{Molecular Mechanisms of Ketamine in Depression}

It has been more than a decade since the antidepressant effect of ketamine was first recognized and yet no single hypothesis can explain the pharmacological basis of ketamine action and the mechanistic pathways of ketamine are not well understood. The involvement of glutamatergic neurotransmission in the pathophysiology of mood disorders has been suggested based on the finding that the level of glutamate, the expression of its receptors and signaling molecules are altered in patients with depression (Choudary et al., 2005; Sanacora et al., 2004; Sanacora et al., 2008; Scarr et al., 2003). The antidepressant effect of ketamine might be simply related to its NMDAR blocking activity. Other NMDAR blockers are reported to be effective in animal model of depression (Moryl et al., 1993). However the molecular consequences following the NMDAR blockade are still unclear. One hypothesis suggests that NMDAR blockade activity of ketamine is associated with further modulation of synaptic plasticity. Ketamine caused an increase in amino hydroxymethylisoxazole propioinc acid receptor (AMPAR)/NMDAR density in the hippocampus in its antidepressant dose (Duman et al., 2012). The blockade of NMDAR allows more glutamate-AMPAR interaction (Tizabi et al., 2012) causing an increase in AMPAergic over NMDAergic signaling (Moryl et al., 1993). Though AMPAR seems to be essential for the antidepressant effect of ketamine (Koike et al., 2011), its actual role is still unclear. AMPAR activity was found to be essential for the fast activation of mammalian target of rapamycin (mTOR) signaling resulting in rapid and sustained elevation of synapse associated proteins and spine number in the prefrontal cortex, changes that are associated with the fast antidepressant effect of ketamine (Akinfiresoye and Tizabi, 2013; Duman et al., 2012; Li et al., 2010). 
Another hypothesis could be based on the ability of ketamine to increase the translation of proteins following NMDAR blockade. Eukaryotic Elongation Factor 2 kinase $(\mathrm{eEF} 2 \mathrm{~K})$ is a serine/threonine kinase that phosphorylates eEF2 and regulates the elongation step of protein translation. It was stated that the blocking of the NMDAR allowed inactivation of eEF2K with subsequent dephosphorylation and activation of eEF2 leading enhancing protein synthesis (Monteggia et al., 2013). Moreover, the inhibitors of eEF2K produce a rapid antidepressant like activity (Autry et al., 2011) that might be related to increase in the Brain Derived Neurotrophic Factor (BDNF) synthesis.

BDNF is a neurotrophic peptide which is highly involved in mood disorders. Increase in the level of BDNF or activation of its related pathway is associated with an antidepressant activity (Hashimoto et al., 2004). Studies that tried to investigate the relationship between the antidepressant effect of ketamine and BDNF showed inconsistent results. Ketamine caused significant increase in hippocampal BDNF level in rats after acute (Garcia et al., 2008a; Yang et al., 2013) but not chronic doses (Garcia et al., 2008b). In another experiment, acute and chronic ketamine treatment did not affect the level of BDNF in hippocampus of rats exposed to chronic mild stress although chronic (but not acute) ketamine treatment caused reversal of anhedonia caused by chronic mild stress (Garcia et al., 2009). Another study showed that prolonged exposure to ketamine over a period of 9 hours increased BDNF mRNA and protein levels in neonatal animals (Ibla et al., 2009). Although ketamine increased the level of BDNF in healthy individuals (Ricci et al., 2011) there was no total change in serum BDNF levels in patients with treatment resistant bipolar disorder. In another study the BDNF plasma level of depressed patients increased only in patients who responded well to ketamine therapy (Haile et al., 2013). The level of BDNF was decreased in serum a week after ketamine dosing in ketamine nonresponders (Rybakowski et al., 2013). Moreover, the $\mathrm{bdnf}^{+}$/- $^{-}$heterozygous null mice showed antidepressant like response to ketamine as wild type mice which may suggest that ketamine can still exert its antidepressant effect through alternate mechanisms (Lindholm et al., 2012). Further molecular and pharmacological characterizations are needed to clarify the degree of contribution of BDNF in the antidepressant effect of ketamine.

The blocking of NMDAR may allow relatively more glutamate available to activate metabotropic glutamate receptors (mGluRs) e.g. GluR5, the enhanced activity of which is claimed to be related to antidepressant effect (Chaki et al., 2013). The role of mGluR seems also to carry some controversy as it has been demonstrated that the blocking of mGluR2/3 caused an antidepressant activity in experimental animals and this antidepressant effect was reduced by inhibiting the BDNF receptor, TrKB, tyrosine kinase activity (Koike et al., 2013). Additional studies are needed to address the differential role of mGluRs in depression.

The monoaminergic mode of action of ketamine has been suggested based on the findings that ketamine inhibited the reuptake of serotonin and norepinephrine (Azzaro and Smith, 1977; Smith et al., 1975). Although this mode of action cannot be ruled-out based on available data, but it seems unlikely to be responsible for the rapid antidepressant effect because if true, the classic amine reuptake inhibitors would have caused the same response, which is not the case as the treatment using Serotonin Selective Reuptake Inhibitors (SSRI) or Serotonin Norepinephrine Reuptake Inhibitors (SNRIs) typically takes weeks to produce evident antidepressant response (Dowben et al., 2013).

\section{The Opioid System and Depression}

The relationship between opioids and depression is as old as early 1900s when opioids were used in the treatment of mood disorders including depression (Tenore, 2008). The involvement of endogenous opioid system in depression was suggested in the early 1980s when it was found that some depressed patients responded to $\beta$-endorphin infusion (Catlin 
et al., 1982; Pickar et al., 1981), an effect that was evident on the first day of therapy. The comorbidity of depression, addiction and chronic pain supports the overlap between the opioid pathways and depression (Hegadoren et al., 2009; Ohayon and Schatzberg, 2003). The limbic areas, the primary areas involved in mood disorders, contain a high density of opioid peptides and receptors (Lutz and Kieffer, 2013).

Endorphins and enkephalins also showed antidepressant-like behavior in animal models (Kastin et al., 1978; Tejedor-Real et al., 1993), while some opioid receptor blockers caused the opposite effect (Torregrossa et al., 2006). Postmortem studies showed an increase in number of mu opioid receptors in depressed patient suggesting that might suggest relative deficiency of their endogenous agonists (Gabilondo et al., 1995). Furthermore, PET studies showed a reduction in mu receptor binding in mood and mood-related disorders associated with fibromyalgia and chronic pain disorders (Harris et al., 2007; Zubieta et al., 2001). Recently more selective opioid receptor agonists and antagonists are being assessed to be utilized in the management of depression. Delta opioid receptor agonists (enkephalins, SNC80 and (+)BW373U86) and kappa receptor antagonists (norbinaltorphimine, $\quad 5$ '-guanidinonaltrindole and $\quad 5$ '-acetamidinoethylnaltrindole) showed significant antidepressant-like effect in animal models (Broom et al., 2002 a,b; Mague et al., 2003; Tejedor-Real et al., 1995). Based on these observations, some opioids are being investigated for treating TRD (Machado-Vieira and Zarate, 2011).

The opioid receptors regulate a number of aspects related to mood disorders including the Hypothalamic Pituitary Axis (HPA) and BDNF. Morphine reduced the activity of the HPA which is known to be hyperactive in depressive states (Hegadoren et al., 2009; Lutz and Kieffer, 2013; Zis et al., 1985) and enhanced BDNF expression in astrocytes (Takayama and Ueda, 2005). Centrally administered $\beta$ endorphin, endomorphin-1 and -2 significantly increased BDNF mRNA expression in frontal cortex, hippocampus and amygdala in a dose-dependent manner. The mu antagonist naloxone completely blocked the increase in BDNF mRNA expression produced by $\beta$-endorphin and endomorphin-1 in all brain regions, and blocked the effect of endomorphin- 2 in the frontal cortex (Zhang et al., 2006). Delta opioid receptor agonists and kappa opioid receptor antagonist upregulated the expression of BDNF in the hippocampus, as well as other brain regions (Torregrossa et al., 2004; Torregrossa et al., 2006; Zhang et al., 2007). However, the behavioral consequence of this opioid-mediated BDNF elevation is not clear and more evidence is needed support the involvement of BDNF in mediating the mode of action of opioids in depression.

\section{Ketamine and the Opioid System; Do They Team up in Depression?}

The friendship between ketamine and opioids is deep. Ketamine seems to act, at least partly, through opioid-mediated pathways. This is supported by accumulating body of evidence. There are some effects that are common to both ketamine and opioids; including sedation, euphoria and analgesia (Prommer, 2012; Ryder et al., 1978). In several studies ketamine was found to potentiate the analgesic effects of opioids (Campos et al., 2006; Wong et al., 1996) even at subaneasthetic doses (Richards and Rockford, 2013). Ketamine was found to directly interact with opioid receptors (Finck et al., 1998; Hirota et al., 1999; Smith et al., 1980a; Yang et al., 2013). It displaced radiolabelled opioids from binding to their receptors centrally (Finck and Ngai, 1982) with more preference for $\mathrm{mu}$ receptors (Garcia et al., 2009; Prommer, 2012). The anesthetic and the analgesic effects of ketamine was reduced by naloxone injected shortly after ketamine in animal models (Finck and Ngai, 1982; Slogoff et al., 1974; Smith et al., 1980b). The reversal of the effects of ketamine by naloxone occurs mainly at the supraspinal levels (Pekoe and Smith, 1982). However, it is not clear if the interaction of ketamine with opioid receptors produces the molecular sequelae similar to opioids. 
There is cross-tolerance between the analgesic effects of morphine and ketamine. Ketamine significantly inhibited symptoms of morphine abstinence produced in morphine-dependent mice by naloxone administration or by morphine withdrawal (Fidecka, 1987). Moreover, ketamine is suggested to release endogenous opioids in vivo (Ryder et al., 1978). Based on that, it is clear that ketamine showed interaction with the endogenous opioid system at different levels. Additional studies are needed to elucidate the molecular signaling cascade following the ketamine-opioid receptor interaction.

Based on the mentioned data, a question raises itself; does the ketamine-induced antidepressant effect is mediated, at least partially, through the stimulation of the opioid system? The BDNF may represent a common language (Figure 1), although other opioid-triggered pathways can be suggested in mediating the antidepressant response (Figure 2). Some of the available data support this hypothesis. The antidepressant effect of ketamine is increased by tramadol. BDNF and TrkB expression increase further when tramadol is combined with ketamine compared to ketamine administration alone (Yang et al., 2012). Tramadol however, should not be regarded as an ideal opioid as it has other modes of actions beside being an opioid receptor agonist (Barber, 2011). Though the available data cannot conclusively support the role of the opioid system in the antidepressant action of ketamine, this hypothesis cannot be ruled out. The opioidmediated action of ketamine might explain some of the effects of ketamine (e.g. euphoria, sedation, analgesia,...) but still it doesn't explain others (e.g. the duration of action). This article is an invitation for researchers to pursue studies addressing this issue. The opioid-mediated antidepressant effect of ketamine can be investigated using opioid receptor knockout mice or by pharmacological blocking of the opioid receptors. I believe that studying the antidepressant mechanisms of ketamine will have a significant impact on our understanding of the pathophysiology of depression.

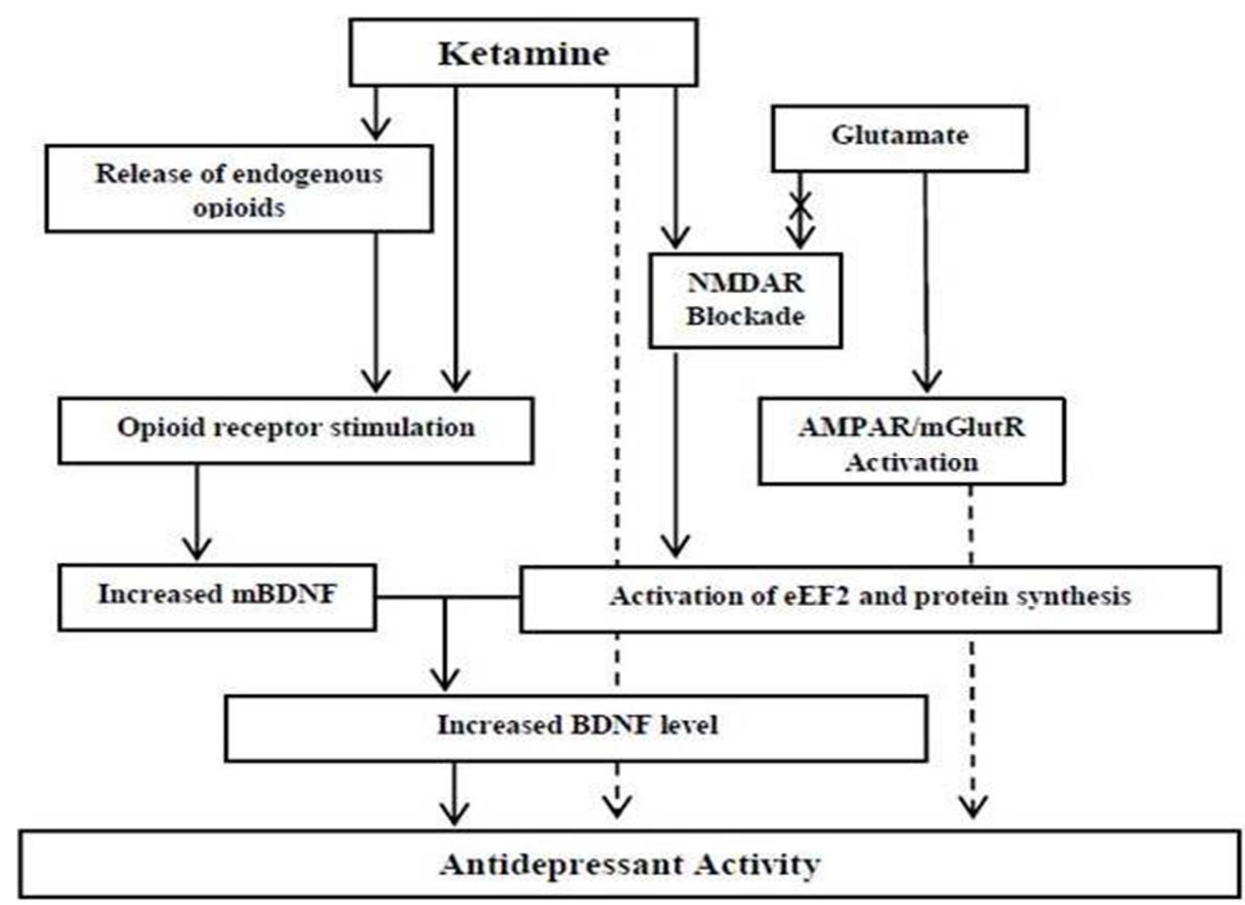

Figure 1. Proposed Mechanism(S) of Action of Ketamine in Depression and the Potential Role of the Opioid System. The BDNF May Represent a Common Language. Dashed Arrows: Unidentified Mechanism 


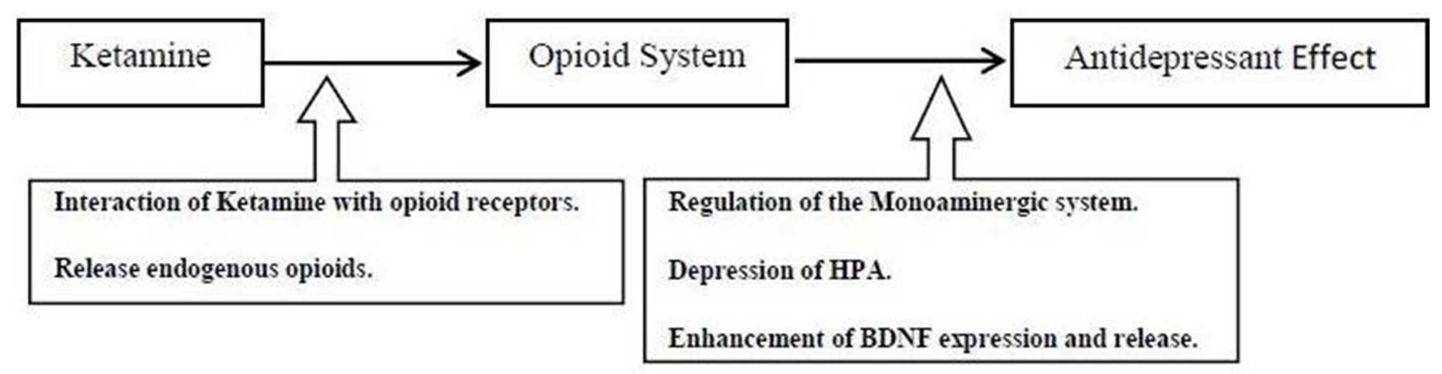

\section{Figure 2. Hypothesis for the Involvement of the Opioid System in the Mechanistic Pathway of Ketamine in Depression}

\section{Acknowledgement}

I would like to gratefully and sincerely thank Dr. Seena Ajit and Dr. Janet Clark for their support during preparing this review.

\section{References}

Aan Het Rot, M., Collins, K. A., Murrough, J. W. et al. (2010). "Safety and Efficacy of Repeated-Dose Intravenous Ketamine for Treatment-Resistant Depression," Biological Psychiatry, 67(2): 139-145.

Akinfiresoye, L. \& Tizabi, Y. (2013). "Antidepressant Effects of AMPA and Ketamine Combination: Role of Hippocampal BDNF, Synapsin, and Mtor," Psychopharmacology (Berl), 230(2):291298.

Autry, A. E., Adachi, M., Nosyreva, E. et al. (2011). "NMDA Receptor Blockade at Rest Triggers Rapid Behavioural Antidepressant Responses," Nature, 475 (7354): 91-95.

Azzaro, A. J. \& Smith, D. J. (1977). "The Inhibitory Action of Ketamine HCI on [53H] Hydroxytryptaminc Accumulation in Rat Brain Synaptosomal-Rich Fractions: Comparison with ["Hjcatecholamine and [ Y-'Hlaminobutyric Acid Uptake," Neuropharmacology, 16(5): 349-356.

Barber, J. (2011). "Examining the Use of Tramadol Hydrochloride as an Antidepressant," Experimental and Clinical Psychopharmacology, 19(2): 123-130.
Berman, R. M., Cappiello, A., Anand, A. et al. (2000). "Antidepressant Effects of Ketamine in Depressed Patients," Biological Psychiatry, 47(4): 351-354.

Broom, D. C., Jutkiewicz, E. M., Folk, J. E. et al. (2002a). "Non-Peptidic Delta-Opioid Receptor Agonists Reduce Immobility in the Forced Swim Assay in Rats," Neuropsychopharmacology, 26(6): 744-755.

Broom, D. C., Jutkiewicz, E. M., Folk, J. E. et al. (2002b). "Convulsant Activity of a NonPeptidic Delta-Opioid Receptor Agonist Is Not Required for Its Antidepressant-Like Effects in Sprague-Dawley Rats," Psychopharmacology (Berl), 164(1): 42-48.

Bunney, B. G. \& Bunney, W. E. (2012). "Rapid-Acting Antidepressant Strategies: Mechanisms of Action," The International Journal of Neuropsychopharmacology, 2012 Jun;15(5):695-713.

Campos, A. R., Santos, F. A. \& Rao, V. S. (2006). "Ketamine-Induced Potentiation of Morphine Analgesia in Rat Tail-Flick Test: Role of Opioid-, Alpha2-Adrenoceptors and ATP-Sensitive Potassium Channels," Biological Pharmacology Bulletin, 29(1): 86-89.

Catlin, D. H., Gorelick, D. A. \& Gerner, R. H. (1982). "Clinical Pharmacology of Betaendorphin in Depression and Schizophrenia," Annals of the New York Academy of Sciences, 398: 434-447. 
Chaki, S., Ago, Y., Palucha-Paniewiera, A. et al. (2013). "mGlu2/3 and mGlu5 Receptors: Potential Targets for Novel Antidepressants," Neuropharmacology, 66: 40-52.

Choudary, P. V., Molnar, M., Evans, S. J. et al. (2005). "Altered Cortical Glutamatergic and Gabaergic Signal Transmission with Glial Involvement in Depression," Proceedings of the Natural Academy of Science USA, 102(43): 15653-15658.

Connolly, K. R. \& Thase, M. E. (2012). "Emerging Drugs for Major Depressive Disorder," Expert Opinion in Emergency Drugs, 17(1): 105-126.

Diazgranados, N., Ibrahim, L. A., Brutsche, N. E. et al. (2010). "Rapid Resolution of Suicidal Ideation after a Single Infusion of an Nmethyl- D-Aspartate Antagonist in Patients with Treatment-Resistant Major Depressive Disorder," Journal of Clinical Psychiatry, 71(12): 1605-1611.

Dillon, P., Copeland, J. \& Jansen, K. (2003). "Patterns of Use and Harms Associated with Non-Medical Ketamine Use," Drug and Alcohol Dependence, 69(1): 23-28.

Dowben, J. S., Grant, J. S. \& Keltner, N. L. (2013). "Biological Perspectives: Ketamine as an Alternative Treatment for TreatmentResistant Depression," Perspectives in Psychiatric Care, 49(1): 2-4.

Duman, R. S., Li, N., Liu, R. J. et al. (2012). "Signaling Pathways Underlying the Rapid Antidepressant Actions of Ketamine," Neuropharmacology, 62(1): 35-41.

Fidecka, S. (1987). "Opioid Mechanisms of Some Behavioral Effects of Ketamine," Polish Journal of Pharmacology and Pharmacy, Jul-Aug;39(4):353-60.

Finck, A. D. \& Ngai, S. H. (1982). "Opiate Receptor Mediation of Ketamine Analgesia," Anesthesiology, 56(4): 291-297.

Finck, A. D., Samaniego, E. \& Ngai, S. H. (1998). "Morphine Tolerance Decreases the Analgesic Effects of Ketamine in Mice," Anesthesiology, 68(3): 397-400.
Gabilondo, A. M., Meana, J. J. \& GarciaSevilla, J. A. (1995). "Increased Density of Muopioid Receptors in the Postmortem Brain of Suicide Victims," Brain Research, 682(1-2): 245-250.

Garcia, L. S. B., Comim, C. M., Valvassori, S. S. et al. (2008a). "Acute Administration of Ketamine Induces Antidepressant Like Effects in the Forced Swimming Test and Increases BDNF Levels in the Rat Hippocampus," Progress in Neuropsychopharmacology and Biological Psychiatry, 32(1): 140-144.

Garcia, L. S. B., Comim, C. M., Valvassori, S. S. et al. (2008b). "Chronic Administration of Ketamine Elicits Antidepressant-Like Effects in Rats without Affecting Hippocampal Brain-Derived Neurotrophic Factor Protein Levels," Basic Clinical Pharmacology and Toxicology, 103(6): 502506.

Garcia, L. S. B., Comim, C. M., Valvassori, S. S. et al. (2009). "Ketamine Treatment Reverses Behavioral and Physiological Alterations Induced by Chronic Mild Stress in Rats," Progress in Neuropsychopharmacol and Biological Psychiatry, 33(3): 450-455.

Haile, C. N., Murrough, J. W., Iosifescu, D. V. et al (2013). "Plasma Brain Derived Neurotrophic Factor (BDNF) and Response to Ketamine in Treatment-Resistant Depression," International Journal of Neuropsychopharmacology :1-6.

Harris, R. E., Clauw, D. J., Scott, D. J. Et al. (2007). "Decreased Central Mu-Opioid Receptor Availability in Fibromyalgia," Journal of Neuroscience, 27(37): 10000 10006.

Hashimoto, K., Shimizu, E. \& Iyo, M. (2004). "Critical Role of Brain-Derived Neurotrophic Factor in Mood Disorders," Brain Research Reviews, 45(2): 104-114.

Hegadoren, K. M., O'Donnell, T., Lanius, R. et al. (2009). "The Role of Beta-Endorphin in the Pathophysiology of Major Depression," Neuropeptides, 43(5): 341353. 
Hirota, K., Sikand, K. S. \& Lambert, D. G. (1999). "Interaction of Ketamine with Mu2 Opioid Receptors in SHSY5Y Human Neuroblastoma Cells," Journal of Anesthesia, 13(2): 107-109.

Ibla, J. C., Hayashi, H., Bajic, D. et al. (2009). "Prolonged Exposure to Ketamine Increases Brain Derived Neurotrophic Factor Levels in Developing Rat Brains," Current Drug Safety, 4(1): 11-16.

Kastin, A. J., Scollan, E. L., Ehrensing, R. H. et al. (1978). "Enkephalin and Other Peptides Reduce Passiveness," Pharmacology Biochemistry and Behavior, 9(4): 515-519.

Koike, H., Fukumoto, K., Iijima, M. et al (2013). "Role of BDNF/TrkB Signaling in Antidepressant Likeeffects of a Group II Metabotropic Glutamate Receptor Antagonist in Animal Models of Depression," Behavioral Brain Research, 238: 48-52.

Koike, H., Iijima, M. \& Chaki, S. (2011). "Involvement of AMPA Receptor in Both the Rapid and Sustained AntidepressantLike Effects of Ketamine in Animal Models of Depression," Behavioral Brain Research, 224(1): 107-111.

Larkin, G. L. \& Beautrais, A. L. (2011). "A Preliminary Naturalistic Study of Low-Dose Ketamine for Depression and Suicide Ideation in the Emergency Department," International Journal of Neuropsychopharmacology 14(8): 11271131.

Li, N., Lee, B., Liu, R. J., et al (2010). " mTORDependent Synapse Formation Underlies the Rapid Antidepressant Effects of NMDA Antagonists," Science, 329: 959-964.

Liebrenz, M., Stohler, R. \& Borgeat, A. (2009). "Repeated Intravenous Ketamine Therapy in a Patient with Treatment Resistant Major Depression," World Journal of Biological Psychiatry, 10(4 Pt2): 640644.
Lindholm, J. S. O., Autio, H., Vesa, L. et al. (2012). "The Antidepressant-Like Effects of Glutamatergic Drugs Ketamine and AMPA Receptor Potentiator LY 451646 Are Preserved in $\mathrm{Bdnf}^{+} /^{-}$Heterozygous Null Mice," Neuropharmacology, 62: 391-7.

Lutz, P. E. \& Kieffer, B. L. (2013). "Opioid Receptors: Distinct Roles in Mood Disorders," Trends in Neuroscience, 36(3): 195-206.

Machado-Vieira, R., Salvadore, G., Diazgranados, N. et al. (2009a). "Ketamine and the Next Generation of Antidepressants with a Rapid Onset of Action," Pharmacology \& Therapeutics 123(2): 143150.

Machado-Vieira, R., Yuan, P., Brutsche, N. et al. (2009b). "Brain-Derived Neurotrophic Factor and Initial Antidepressant Response to an N-Methyl D-Aspartate Antagonist," Journal of Clinical Psychiatry, 70(12): 16621666.

Machado-Vieira, R. \& Zarate, C. A. Jr (2011). "Proof of Concept Trials in Bipolar Disorder and Major Depressive Disorder: A Translational Perspective in the Search for Improved Treatments," Depression and Anxiety,28(4): 267-281.

Mague, S. D., Pliakas, A. M., Todtenkopf, M. S. et al. (2003). "Antidepressant-Like Effects of Kappa-Opioid Receptor Antagonists in the Forced Swim Test in Rats," Journal of Pharmacology and Experimental Therapeutics, 305(1): 323330.

Mathew, S. J., Murrough, J. W., Aan Het Rot, M. et al. (2010). "Riluzole for Relapse Prevention Following Intravenous Ketamine in Treatment-Resistant Depression: A Pilot Randomized, PlaceboControlled Continuation Trial," International Journal of Neuropsychopharmacolgy, 13(1): 71-82. 
Mathew, S. J., Shah, A., Lapidus, K. et al. (2012). "Ketamine for Treatment-Resistant Unipolar Depression: Current Evidence," CNS Drugs, 26(3): 189- 204.

Monteggia, L. M., Gideons, E. \& Kavalali, E. T. (2013). "The Role of Eukaryotic Elongation Factor 2 Kinase in Rapid Antidepressant Action of Ketamine," Biological Psychiatry, 73(12): 1199-1203.

Moryl, E., Danysz, W. \& Quack, G. (1993). "Potential Antidepressive Properties of Amantadine, Memantine and Bifemelane," Pharmacology \& Toxicology, 72(6): 394397.

Ohayon, M. M. \& Schatzberg, A. F. (2003). "Using Chronic Pain to Predict Depressive Morbidity in the General Population," Archives of General Psychiatry, 60(1): 3947.

Pekoe, G. M. \& Smith, D. J. (1982). "The Involvement of Opiate and Monoaminergic Neuronal Systems in the Analgesic Effects of Ketamine," Pain 12(1): 57-73.

Pickar, D., Davis, G. C., Schulz, S. C. et al. (1981). "Behavioral and Biological Effects of Acute Beta-endorphin Injection in Schizophrenic and Depressed Patients," American Journal of Psychiatry, 138(2): 160-166.

Prommer, E. E. (2012). "Ketamine for Pain: An Update of Uses in Palliative Care," Journal of Palliative Medicine, 15(4): 474483.

Ricci, V., Martinotti, G., Gelfo, F. et al. (2011). "Chronic Ketamine Use Increases Serum Levels of Brain-Derived Neurotrophic Factor," Psychopharmacology (Berl), 215(1): 143-148.

Richards, J. R. \& Rockford, R. E. (2013). "Low-Dose Ketamine Analgesia: Patient and Physician Experience in the ED," American Journal of Emergency Medecine, 31(2):390-394.
Rush, A. J., Trivedi, M. H., Wisniewski, S. R. et al. (2006). "Acute and Longer-Term Outcomes in Depressed Outpatients Requiring One or Several Treatment Steps: A STAR*D Report," American Journal of Psychiatry, 163(11): 1905-1917.

Rybakowski, J. K., Permoda-Osip, A., Skibinska, M. et al. (2013). "Single Ketamine Infusion in Bipolar Depression Resistant to Antidepressants: Are Neurotrophins Involved?," Human Psychopharmacology, 28(1): 87-90.

Ryder, S., Way, W. L. \& Trevor, A. J. (1978). "Comparative Pharmacology of Optical Isomers of Ketamine in Mice," European Journal of Pharmacology, 49(1): 15-23.

Sanacora, G., Gueorguieva, R., Epperson, C. N. et al. (2004). "Subtypespecific Alterations of Gamma-Aminobutyric Acid and Glutamate in Patients with Major Depression," Archives in General Psychiatry, 61(7): 705-713.

Sanacora, G., Zarate, C. A., Krystal, J. H. et al. (2008). "Targeting the Glutamatergic System to Develop Novel, Improved Therapeutics for Mood Disorders," Nature Reviews Drug Discovery, 7(5): 426- 437.

Scarr, E., Pavey, G., Sundram, S. et al. (2003). "Decreased Hippocampal NMDA, but Not Kainate or AMPA Receptors in Bipolar Disorder," Bipolar Disorders, 5(4): 257-264.

Slogoff, S., Allen, G. W., Wessels, J. V. et al. (1974). 'Clinical Experience with Subanesthetic Doses of Ketamine,' Anesthesia \& Analgesia, 53(3): 354-358.

Smith, D. J., Azzaro, A. J., Turndorf, H. et al. (1975). "The Effect of Ketamine HCI on the Invitro Metabolism of Norepinephrine in Rat Cerebral Cortex Tissue," Neuropharmacology,14(7): 473-448. 
Smith, D. J., Pekoe, G. M., Martin, L. L. et al. (1980a). "The Interaction of Ketamine with the Opiate Receptor," Life Sciences, 26(10): 789-795.

Smith, D. J., Westfall, D. P. \& Adams, J. D. (1980b). "Ketamine Interacts with Opiate Receptors as an Agonist," Anesthesiology, 53:S5.

Takayama, N. \& Ueda, H. (2005). "Morphine-Induced Chemotaxis and BrainDerived Neurotrophic Factor Expression in Microglia," Journal of Neuroscience, 25(2): 430-435.

Tejedor-Real, P., Micó, J. A., Maldonado, R. et al. (1993). "Effect of Mixed (RB 38A) and Selective (RB 38B) Inhibitors of Enkephalin Degrading Enzymes on a Model of Depression in the Rat," Biological Psychiatry, 34(1-2): 100-107.

Tejedor-Real, P., Mico, J. A., Maldonado, R. et al. (1995). "Implication of Endogenous Opioid System in the Learned Helplessness Model of Depression," Pharmacology Biochemistry and Behavior, 52(1): 145-152.

Tenore, P. L. (2008). "Psychotherapeutic Benefits of Opioid Agonist Therapy," Journal of Addictive Disease, 27(3): 49-65.

Thakurta, R. G., Ray, P., Kanji, D. et al. (2012). "Rapid Antidepressant Response with Ketamine: Is It the Solution to Resistant Depression?," Indian Journal of Psychological Medicine, 34(1): 56-60.

Tizabi, Y., Bhatti, B. H., Manaye, K. F. et al. (2012). "Antidepressant-Like Effects of Low Ketamine Dose Is Associated with Increased Hippocampal AMPA/NMDA Receptor Density Ratio in Female WistarKyoto Rats," Neuroscience, 213: 72-80.

Torregrossa, M. M., Isgor, C., Folk, J. E. et al. (2004). "The Delta-Opioid Receptor Agonist (+)BW373U86 Regulates BDNF Mrna Expression in Rats," Neuropsychopharmacology, 29(4): 649-659.
Torregrossa, M. M., Jutkiewicz, E. M., Mosberg, H. I. et al. (2006). "Peptidic Delta Opioid Receptor Agonists Produce Antidepressant-Like Effects in the Forced Swim Test and Regulate BDNF Mrna Expression in Rats," Brain Research, 1069(1): 172-181.

Wong, C. S., Liaw, W. J., Tung, C. S. et al. (1996). "Ketamine Potentiates Analgesic Effect of Morphine in Postoperative Epidural Pain Control," Regional Anesthesia, 21(6): 534-541.

Yang, C., Hu, Y. M., Zhou, Z. Q. et al. (2013). "Acute Administration of Ketamine in Rats Increases Hippocampal BDNF and Mtor Levels during Forced Swimming Test," Upsala Journal of Medical Science, 118(1): 3-8.

Yang, C., Li, X., Wang, N. et al. (2012). "Tramadol Reinforces Antidepressant Effects of Ketamine with Increased Levels of Brain-Derived Neurotrophic Factor and Tropomyosin-Related Kinase B in Rat Hippocampus," Frontiers of Medicine, 6(4): 411-415.

Zarate, C. A. Jr, Brutsche, N., Laje, G. et al. (2012). "Relationship of Ketamine's Plasma Metabolites with Response, Diagnosis, and Side Effects in Major Depression," Biological Psychiatry, 72(4): 331-338.

Zarate, C. A. Jr, Singh, J. B., Carlson, P. J. et al. (2006). "A Randomized Trial of an NMethyl-D-Aspartate Antagonist in Treatmentresistant Major Depression," Archives of General Psychiatry, 63(8): 856864.

Zhang, H., Shi, Y. G., Woods, J. H. et al. (2007). "Central Kappa-Opioid ReceptorMediated Antidepressant-Like Effects of Nor-Binaltorphimine: Behavioral and BDNF Mrna Expression Studies," European Journal of Pharmacology, 570(1-3): 89-96.

Zhang, H., Torregrossa, M. M., Jutkiewicz, E. M. et al. (2006). "Endogenous Opioids Upregulate Brain-Derived Neurotrophic Factor Mrna through Delta- and MicroOpioid Receptors Independent of 
Antidepressant-Like Effects," European Journal of Neuroscience, 23(4): 984-994.

Zis, A. P., Haskett, R. F., Albala, A. A. et al. (1985). "Opioid Regulation of Hypothalamic Pituitary-Adrenal Function in Depression," Archives of General Psychiatry, 42(4): 383-386.

Zubieta, J. K., Smith, Y. R., Bueller, J. A. et al. (2001). "Regional Mu Opioid Receptor Regulation of Sensory and Affective Dimensions of Pain," Science, 293(5528): 311-315. 